\title{
Diverse perspectives on student agency in classroom assessment
}

\author{
${\text { Lenore Ellen } \text { Adie }^{1} \text { (D) Jill Willis }}^{2}$ (D) Fabienne Michelle Van der Kleij ${ }^{1}$
}

Received: 29 January 2018/ Accepted: 31 January 2018/Published online: 17 February 2018

(C) The Australian Association for Research in Education, Inc. 2018

Internationally, notions of assessment usually conjure up images of tests conducted in formal examination conditions, and of large-scale assessments that enable national and international comparisons. Student and teacher perspectives on what counts as valuable learning, and what assessment measures count as valid are rarely represented as evidence of quality learning in this highly political and historical construct of assessment. Classrooms, as sites of learning, are increasingly driven by systemic imperatives, and regulated by the collection of data, where teachers and students are held to account through observations and audits. Assessment is exteriorised as a performance within cultures of surveillance and risk management (Page 2017). Within these performative cultures, historically and in current times, students have been the objects of assessment processes with teachers or external testing bodies controlling the field of evaluation and judgement. In the past half century, amid a call to link assessment and learning, the focus of classroom assessment practices has shifted from purely summative to a continuum of summative-formative, aiming to both judge and improve learning, and to give greater consideration to the social and cultural patterns in informal as well as formal assessment interactions.

\section{Lenore Ellen Adie}

lenore.adie@acu.edu.au

https://lsia.acu.edu.au/people/dr-lenore-adie

Jill Willis

http://staff.qut.edu.au/staff/willisje

Fabienne Michelle Van der Kleij

https://lsia.acu.edu.au/people/dr-fabienne-van-der-kleij/

1 Learning Sciences Institute Australia, Australian Catholic University, Level 4, 229 Elizabeth Street, Brisbane 4000, Australia

2 Faculty of Education, Queensland University of Technology, 149 Victoria Park Rd, Kelvin Grove, Brisbane 4059, Australia 
When assessment and learning are considered together, students take a central role and are expected to understand themselves as learners, contributing to the construction of knowledge (Black et al. 2003). A focus on student agency in assessment acknowledges students as actors who make choices, and whose actions shape assessment practices in both anticipated and unexpected ways. In particular, it is through formative assessment that students come to understand the learning context, for example, expected criteria and standards, and have the opportunity to develop increasing agency over their own learning (Clark 2012; Smith et al. 2016). However, while the centrality of students in assessment practices is firmly grounded in assessment for learning theory, evidence of enacted practice suggests that there are still limited opportunities for students to take up this role in the classroom (Evans 2013; Hawe and Parr 2014). The papers in this issue explore how this expectation might be realised.

This Special Issue of AER provides an opportunity for authors from five countries to critically examine classroom assessment practices that focus on enhancing student agency. Just as the focus of classroom assessment has shifted over time to include a greater understanding of the social dynamics, concepts of agency have developed from a focus on the rational individual as agent, to include the complex interdependence of individual agency and social contexts (Eteläpelto et al. 2013). Priestley et al. (2015) state that "Agency is not something that people can have or possess; it is rather to be understood as something that people do or achieve" (p. 22). In framing the call for this Special Issue, we drew on a wellestablished definition of agency by Emirbayer and Mische (1998) that emphasises the interplay of agents and their contexts. Agency is:

temporally constructed engagement by actors of different structural environments - the temporal-relational contexts of action-which, through the interplay of habit, imagination and judgment, both reproduces and transforms those structures in interactive response to the problems posed by changing historical situations. (p. 971)

The definition identifies important interlinked dimensions of agency that enable significant ideas from contextualised studies in classroom assessment to be considered together and mutually inform the development of the idea of student agency.

The three key concepts from this definition that are of significance to this Special Issue are:

- Actors-Students and teachers co-construct assessment practices through their choices and actions. In this issue on student agency, many of the articles focus on the work of teachers as they seek to enhance opportunities for student agency through assessment activities. This reflects the broader state of the field that focuses on teacher action rather than student perspectives, a limitation noted in the conclusion.

- Contexts-The term student agency has been deliberately used instead of learner agency in this issue to foreground classroom assessment situated within 
educational environments where teachers retain the majority of the power and control in setting curriculum and assessment goals. The articles consider how various historical, theoretical, relational and formal and informal structural contexts constrain or enable student choices and actions in assessment.

- Actions-At the centre of each article is a focus on understanding how students might learn to make choices in assessment that empower and engage them as owners of their learning and assessment. Habit acknowledges that actors draw selectively on past patterns and experiences to give stability that sustains identities and institutions over time, while imagination foregrounds the generative ways actors create new possibilities for current and future actions. Many of the articles in this Special Issue focus on the ways that students learn to make practical judgements in immediate assessment activities, and draw on a range of diverse theoretical resources to propose actions that can develop and maintain student agency.

Figure 1 draws together some of these key ideas from the Emirbayer and Mische (1998) definition and embeds them within the context of classroom assessment.

\section{Students as agents in assessment contexts: Choices and actions}

The active role of students in their learning has long been articulated in educational philosophy, yet has remained elusive as enacted classroom practice operationalised across education systems. Historically, teacher-centric learning environments delegated students as passive participants in their learning, rather than providing opportunities for active voice and agency in assessment decisions. Dewey (1961/1943) advocated for student-centred classrooms, with students taking an active role in their learning and meaning construction. Fullan (1991) asked "What would happen if we treated the student as someone whose opinion mattered...?" (p. 170). While Fullan was referring to school reform, his sentiment equally applies to student involvement in assessment processes.

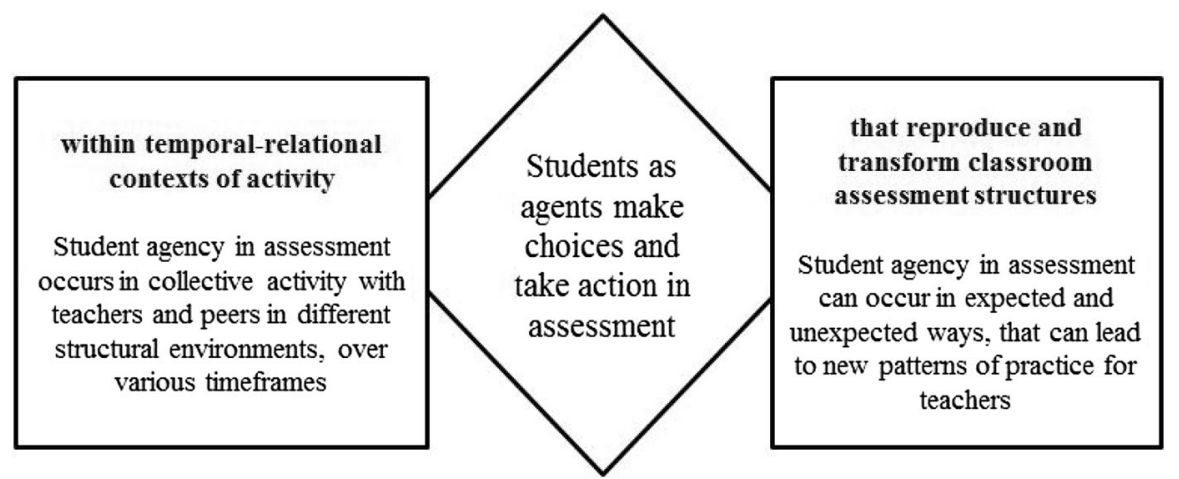

Fig. 1 Different aspects of the interdependent interactions of actors, contexts and actions (based on Emirbayer and Mische 1998) 
Student agency in assessment can take many forms and can happen to varying degrees dependent on aspects such as opportunities to voice their opinions, and to learn skills of self-evaluation. One of the ways in which student agency has been explicitly linked to assessment and learning is through self-regulation. Students make choices on how to act and which strategies to employ, depending on the relational and physical conditions and contexts for accessing information in order to construct new knowledge schematas (Clark 2012). Studies in human agency draw from a range of concepts including those of self-efficacy, motivation, and selfregulatory processes (Smith et al. 2016). Based on the work of Bandura, Smith et al. (2016) identified three factors that influence agency: "(1) personal factors such as cognition, (2) affect and biological events, and (3) behaviour and environmental influences" (p. 7). To exercise agency in assessment practice, students draw on a diverse mix of discipline and process knowledges, responsive to variables such as age, culture, gender and ability. The degree of influence of each factor is dependent on the sociocultural context of performance which can act to support or hinder opportunity for students to act with imagination and agency.

Empowering students to take various roles in assessment processes moves them beyond simply responding to a question or task designed by the teacher. Students may engage in peer and self-assessment, assessing their classmate's or their own work. Many authors have stressed the importance of students understanding the criteria and standards upon which they are being judged so that they can habitually monitor their own performance (e.g. Boud and Molloy 2013; Sadler 1989). They can be given responsibility to collect and identify evidence that best demonstrates their learning (Cumming and Van der Kleij 2016). These roles are understood as opportunities to be inducted "into the rules of the particular academic community... [addressing] fundamental student needs such as competency, autonomy (selfdetermination), and relatedness (meaning making) so that students can feel that they make a valuable contribution as members of such communities" (Evans 2013, p. 106).

In this issue, Panadero, Andrade and Brookhart review the development of the complementary fields of self-regulated learning and formative assessment. They trace how these two specialised fields have developed to be mutually informing. Over that time there has been a greater attention to student involvement in assessment through self and peer assessment, and a focus on how students can contribute to co-regulation of learning through assessment. The co-construction of student agency is a focus of several articles in this issue. Heritage and Rodgers illustrate how students develop ownership over their learning with the guidance of subtle scaffolding and feedback, while Harris, Brown and Dargusch reflect that students can be agentic in assessment, yet not necessarily in ways that teachers expect. In the article by Bourke, O'Neill and Loveridge, students are positioned as initiators and experts who draw on their previous learning in informal activities to inform their assessment roles in their formal schooling contexts. Students learn to enact specific expectations as they are positioned, or position themselves to initiate actions within assessment contexts (Kumpulainen et al. 2014). 


\section{Student agency is situated in temporal-relational contexts of activity}

The relationship between student agency and assessment therefore needs to be understood within the circumscribed structures and reflective practices within different temporal and relational configurations of the classroom. In tracing the dominant western ideal of a rational autonomous individual, Devine and Irwin (2005) recognise the tensions that knowledge of self can only exist in the context of the knowledge of its own society. Agency cannot therefore be considered as separate to capacity and context but has to be considered as integrated and mutually informing concepts. They define agency as "not individuated freedom of will... [but rather] the hesitant bringing forth of reflective thinking and practices on the contexts, the parameters and the effects of mode of behaviour (individual and communal)" (Devine and Irwin 2005, p. 329).

In western liberal democracies, agency or autonomy is recognised as the "goal towards which we educate adolescents...[the] ultimate condition of adulthood" (Devine and Irwin 2005, p. 321). The role of education is therefore to develop the rationality that will achieve that autonomy, which assumes that agency is a developmental goal that is yet to be realised. These assumptions influence the structure and emphasis within curriculum and assessment programs, with student choices often delayed until the later years of schooling. Yet, research has identified that even children as young as 6 and 7 years old, given the right context, are able to articulate their strategies for regulating their learning and their need for autonomy in their learning process (Tunstall and Gipps 1996). Students from the age of 6 in Hong Kong were also able to report their awareness of assessment cultural expectations, for example that their parents had high expectations for achievement that led to some pressure to achieve in assessment (Carless and Lam 2014). Choices for students are highly circumscribed by the context of official decisions and regulations. Cultural and parental expectations over the immediate and long term are also part of the temporal contexts of activity that shape the possibilities for student agency.

Student agency in classroom assessment practices is also tightly intertwined with teacher actions. Boud and Molloy (2013) have described teachers as "designers and sustainers of the learning milieu; establishing the conditions in which students can operate with agency" (p. 710). Thus, classroom assessment practices that are considered to be fair will include opportunities for students to develop assessment knowledge so that they have the skills to use assessment information from a range of sources. Students have associated greater fairness in assessment with more frequent formative interactions with teachers where the teachers make connections between assessment and learning (Murillo and Hidalgo 2017). When teachers frame learning within disciplinary norms, students can demonstrate autonomy that goes beyond a procedural competency (Cowie and Moreland 2015). However, the relational contexts for assessment between teachers and students are not always productive contexts for student agency. Peterson and Irving (2008) in a study in secondary education showed that students rarely took actions to improve their learning based on feedback. What is more, they failed to take responsibility for the lack of 
subsequent improvements in their learning outcomes, but rather blamed their teachers. Interestingly, Marshall and Drummond (2006) identified that it was when teachers did take greater responsibility for student failure that assessment led to more effective assessment for learning and increased student ownership of learning. When teachers develop assessment patterns of participation that lead to a mutual engagement in learning with students, a joint responsibility for assessment outcomes has been shown to develop (Cowie 2005; Willis 2011).

The co-constructing actions of teachers in their formal classroom assessment processes in the USA are explored in this issue by Heritage and Rodgers. Heritage focuses on the co-regulation of learning which occurs as teachers skilfully prompt, scaffold and nudge student thinking through classroom dialogue, to position students as knowledgeable people who can solve problems and construct understanding. Rodgers' focus is on descriptive feedback in which students provide feedback to the teacher on their experience as a learner. In this dialogical process, students acquire the language to talk about their learning, and in doing so exercise agency to inform pedagogic practices that will support their learning. Braund and DeLuca's article reports on the ways that teacher beliefs can influence the opportunities for students to develop metacognitive awareness through formative assessment in Canadian elementary classrooms. Metacognitive control occurred across a range of assessment activities to different degrees. Bourke, O'Neill and Loveridge write that New Zealand primary school teachers had their assessment beliefs and practices productively challenged when they began to draw on student cultural knowledge from their learning outside of school to inform ipsative classroom assessment. Students could confidently articulate their strategies for selfassessment, and take leadership in learning. The article by Graham, Tancredi, Willis and McGraw highlights a dilemma arising from the use of rubrics and assessment task sheets that are often designed to support student agency. These assessment resources may inadvertently contribute additional barriers to student agency in assessment, particularly for students with disabilities. Accessible design is a condition for equitable opportunity for students to demonstrate agency. A key implication of all of these articles is that there must be the commitment by others (for example, teachers, peers, school leaders) to listen to, and act upon all views so that student engagement in assessment practices is maintained, and assessment practices themselves are open to transformation (Aitken 2012; Barrance and Elwood 2018).

\section{Students as agents reproduce and transform classroom assessment structures}

When students are positioned as people who make choices, and take control over their learning through assessment activities, traditions of power and control in classrooms can be disrupted. This is especially the case when standardised tests, and increasing regimes of assessment data collection work to create fields of judgement that hold teachers and students to account, and determine what learning is valued (Ball 2003). Within highly regulated assessment systems, students are often 
discussed as subjects of top-down policy, and student initiated assessment choices are restricted to matters of small significance, such as choice of topics.

However, in recent times, student agency has moved from the sideline to become a major focus of assessment policy reform internationally, with accounts being gathered of this shift. For example, in the UK, Barrance and Elwood (2018) showed how "students are able to provide powerful insights on GCSE assessments" (p. 14), calling for the involvement of students in national, as well as local, decision-making regarding assessment policy and practices. In New Zealand, the newly elected Labour government has prioritised the role of individual students to take responsibility for their progress, and promised an end to the requirement for assessment and reporting against national standards (New Zealand Ministry of Education 2017). Student agency has also been positioned as a central feature of the emerging policy in the USA, as the Every Student Succeeds Act (ESSA) has signalled a shift away from a nationally controlled system, to a requirement for states to articulate a vision and goals for educational assessment design with many considering student agency as a foregrounded priority (Guha et al. 2018; Heritage 2018a). In Australia, student agency is implied within broad aspirational goals that describe desirable characteristics of creative and critical citizens who possess a range of 21st century skills (Ministerial Council on Education, Employment, Training and Youth Affairs 2008). Australian school principals have also recently identified student agency as a significant priority that is broadly defined through links to engagement (Anderson et al. 2017).

While there is evidence that the concept of student agency is gaining influence in international assessment policy, it remains an ill-defined concept in assessment literature, signalling a need for critical accounts of how student agency is understood, through various theoretical lenses, and as enacted in diverse classroom contexts. Critical accounts can provide insights into how students can develop control over fields of judgement and contribute to the construction of knowledge. These accounts further illustrate how teachers can develop new patterns of practice when they actively encourage student involvement in dialogic assessment conversations (Van der Kleij et al. 2017). Greater student mastery in assessment is established by enabling students to do more than tinker at the edges of assessment; it requires students to engage in developing the guild knowledge of assessment connoisseurship to recognise quality in their work (Sadler 1989).

In contrast, but of equal importance to an understanding of student agency in assessment practices, is research that explores how classroom assessment structures are transformed when opportunities for agency are resisted. The possibilities of students as active agents who resist assessment requirements is one that is not often explored. Student agency can be a fluid performance of power, where apparent resistance to teacher instruction can lead to students developing deeper understanding (Charteris 2016). In high performance cultures, student agency may not be seen as desirable, and parents and students may resist teacher efforts to move away from historic notions of the roles of teachers and students (Charteris and Thomas 2017; Evans 2013; Harris and Brown 2013). Yet it is in acts of resistance, that new practices can evolve. 
In this Special Issue, Harris, Brown and Dargusch report on research exploring the behaviours of primary and secondary students in New Zealand and first year university students in Australia to resist engagement in assessment practices. The students' agency is evident in their choices and motives for resisting assessment for learning, so that egos are protected and a sense of psychological safety is maintained. Actions informed by past events or habit are performed in the present but offer the possibility for transforming assessment practices through imagination and the generation of new ways of responding by teachers and students.

\section{A call for more evidence}

This Special Issue was an invitation to authors to explore how social processes that develop the mutual engagement of teachers and students in learning through assessment can be identified and sustained. In doing so, it seeks to begin a conversation bringing together multiple perspectives on student agency and assessment that will enhance the opportunities for student agency through assessment, inform both policy and practice, and lead to insights and directions for further research.

In a recent systematic review of studies focussing on the role of students in assessment, Dinsmore and Wilson (2017) concluded that there is currently a lack of evidence regarding the benefits of student participation in assessment practices, although the authors did not discard the notion that "participation in assessment can be beneficial in terms of self-regulation" (p. 164). The range of papers in the Special Issue contribute to filling some of these 'evidence gaps' by addressing student agency in assessment from a variety of lenses-clarity of assessment information through the design of assessment task sheets (Graham et al. 2018); the importance of knowing students through careful dialogue (Heritage 2018b), descriptive feedback (Rodgers 2018) and through their out-of-school activities (Bourke et al. 2018); enhancing student metacognition (Braund and DeLuca 2018; Panadero et al. 2018); and understanding student resistance to assessment practices (Harris et al. 2018). There is still a need for more research through large-scale studies and through the intense gaze of small localised studies. The framework of Fig. 1 highlights ideas from a well-established definition of agency (Emirbayer and Mische 1998), proposes concepts to support understanding of the conditions for developing student agency, and suggests a shared language that may enable diverse studies to build towards a coherent picture of student agency in assessment.

More insights are needed from students about how they can and would like to contribute to assessment practices. We acknowledge the limitations of representation in the Special Issue: for example, none of the papers represent students from Confucian cultures; or students as co-researchers investigating best approaches to assessment and learning, as proposed by Mockler and Groundwater-Smith (2014). Similarly, there remains scope for more empirical research that explores how curriculum orientations shape the expectations for characteristics that are valued as agentic; and to understand how teachers and students work together-in particular circumstances-managing shifts in power relationships, adjusting learning in 
feedback cycles and learning from one another. The questions that provided a focus for the Special Issue have begun to be answered, but there is more work still to be done:

- How do students construct their engagement in classroom assessment, particularly those students who may not traditionally experience success?

- Can innovative structural environments such as digital tools, new generation learning spaces or authentic assessment designs enable greater student agency in classroom assessment?

- What temporal-relational contexts of action are needed to support feedback that leads to self-regulation and metacognition?

- In what ways do imagination and habit enable students to develop greater control over their ability to practically evaluate their day to day learning?

- How might intersections of summative and formative assessment be re-imagined to enhance student control over their learning?

- When do disruptions to institutional classroom assessment practices lead to the transformation of those structures in ways that enhance student control of learning?

- How might research methodologies that privilege student perspectives provide alternative understandings of assessment quality?

We look forward to others taking up these research questions and responding to the call for evidence of the impact of enacted student agency on assessment practices and student learning.

\section{References}

Aitken, N. (2012). Student voice in fair assessment practice. In C. F. Webber \& J. Lupart (Eds.), Leading Student Assessment (pp. 175-200). Dordrecht: Springer.

Anderson, M., Hinz, B., \& Matus, H. (2017). The paradigm shifters: Entrepreneurial learning in schools. Resource document. Retrieved 25 January, 2017 from http://www.mitchellinstitute.org.au/wpcontent/uploads/2017/11/Paradigm-Shifters_entrepreneurial-learning-in-schools.pdf.

Ball, S. J. (2003). The teacher's soul and the terrors of performativity. Journal of education policy, 18, 215-228. https://doi.org/10.1080/0268093022000043065.

Barrance, R., \& Elwood, J. (2018). National assessment policy reform 14-16 and its consequences for young people: student views and experiences of GCSE reform in Northern Ireland and Wales. Assessment in Education: Principles, Policy \& Practice. https://doi.org/10.1080/0969594X.2017. 1410465.

Black, P., Harrison, C., Lee, C., Marshall, B., \& Wiliam, D. (2003). Assessment for learning: Putting it into practice. Maidenhead: Open University.

Boud, D., \& Molloy, E. (2013). Rethinking models of feedback for learning: The challenge of design. Assessment \& Evaluation in Higher Education, 38, 698-712. https://doi.org/10.1080/02602938. 2012.691462.

Bourke, R., O’Neill, J., \& Loveridge, J. (2018). What starts to happen to teachers' assessment when they learn about their children's informal learning? The Australian Educational Researcher, 45. https:// doi.org/10.1007/s13384-018-0259-x.

Braund, H., \& Deluca, C. (2018). Elementary students as active agents in their learning: An empirical study of the connections between assessment practices and student metacognition. The Australian Educational Researcher, 45. https://doi.org/10.1007/s13384-018-0265-z. 
Carless, D., \& Lam, R. (2014). The examined life: Perspectives of lower primary school students in Hong Kong. Education, 3-13(42), 313-329. https://doi.org/10.1080/03004279.2012.689988.

Charteris, J. (2016). Envisaging agency as discourse hybridity: A Butlerian analysis of secondary classroom discourses. Discourse: Studies in the Cultural Politics of Education, 37, 189-203. https:// doi.org/10.1080/01596306.2014.943156.

Charteris, J., \& Thomas, E. (2017). Uncovering 'unwelcome truths' through student voice: teacher inquiry into agency and student assessment literacy. Teaching Education, 28, 162-177. https://doi. org/10.1080/10476210.2016.1229291.

Clark, I. (2012). Formative assessment: Assessment is for self-regulated learning. Educational Psychology Review, 24, 205-249. https://doi.org/10.1007/s10648-011-9191-6.

Cowie, B. (2005). Pupil commentary on assessment for learning. The Curriculum Journal, 16, 137-151. https://doi.org/10.1080/09585170500135921.

Cowie, B., \& Moreland, J. (2015). Leveraging disciplinary practices to support students' active participation in formative assessment. Assessment in Education: Principles, Policy \& Practice, 22, 247-264. https://doi.org/10.1080/0969594X.2015.1015960.

Cumming, J. J., \& Van der Kleij, F. M. (2016). Effective enactment of Assessment for Learning and student diversity in Australia. In D. Laveault \& L. Allal (Eds.), Assessment for Learning: Meeting the Challenge of Implementation (pp. 55-73). Dordrecht: Springer.

Devine, N., \& Irwin, R. (2005). Autonomy, agency and education: He tangata, he tangata, he tangata. Educational Philosophy and Theory., 37, 317-331. https://doi.org/10.1111/j.1469-5812.2005.00122. $\mathrm{x}$.

Dewey, J. (1961|1943). The school and society (Revised ed.). Chicago: University of Chicago.

Dinsmore, D. L., \& Wilson, H. E. (2017). Student participation in assessment: Does it influence selfregulation? In G. Brown \& L. Harris (Eds.), Handbook of human and social conditions in assessment (pp. 145-185). New York: Routledge.

Emirbayer, M., \& Mische, A. (1998). What is agency? American Journal of Sociology, 103, 962-1023. https://doi.org/10.1086/231294.

Eteläpelto, A., Vähäsantanen, K., Hökkä, P., \& Paloniemi, S. (2013). What is agency? Conceptualizing professional agency at work. Educational Research Review, 10, 45-65. https://doi.org/10.1016/j. edurev.2013.05.001.

Evans, C. (2013). Making sense of assessment feedback in higher education. Review of Educational Research, 83, 70-120. https://doi.org/10.3102/0034654312474350.

Fullan, M. (1991). The new meaning of educational change. New York: Teachers College Press.

Graham, L. J., Tancredi, H., Willis, J., \& McGraw, K. (2018). Designing out barriers to student access and participation in teacher developed secondary school assessment. The Australian Educational Researcher, 45. https://doi.org/10.1007/s13384-018-0266-y.

Guha, R., Wagner, T., Darling-Hammond, L., Taylor, T., \& Curtis, D. (2018). The promise of performance assessments: Innovations in high school learning and college admission. Palo Alto: Learning Policy Institute.

Harris, L. R., \& Brown, G. T. L. (2013). Opportunities and obstacles to consider when using peer- and self-assessment to improve student learning: Case studies into teachers' implementation. Teaching and Teacher Education, 36, 101-111. https://doi.org/10.1016/j.tate.2013.07.008.

Harris, L., Brown, G. T. L., \& Dargusch, J. (2018). Not playing the game: Student assessment resistance as a form of agency. The Australian Educational Researcher, 45. https://doi.org/10.1007/s13384018-0264-0.

Hawe, E., \& Parr, J. (2014). Assessment for Learning in the writing classroom: An incomplete realisation. The Curriculum Journal, 25, 210-237. https://doi.org/10.1080/09585176.2013.862172.

Heritage, M. (2018a). Changing the assessment relationship to empower teachers and students. In K. L. McClarty, K. D. Mattern, \& M. N. Gaertner (Eds.), Preparing students for college and careers: theory, measurement, and educational practice (pp. 153-165). New York: Routledge.

Heritage, M. (2018b). Assessment for learning as support for student self-regulation. The Australian Educational Researcher, 45. https://doi.org/10.1007/s13384-018-0261-3

Kumpulainen, K., Lipponen, L., Hilppö, J., \& Mikkola, A. (2014). Building on the positive in children's lives: a co-participatory study on the social construction of children's sense of agency. Early Child Development and Care, 184, 211-229. https://doi.org/10.1080/03004430.2013.778253.

Marshall, B., \& Drummond, J. (2006). How teachers engage with assessment for learning: Lessons from the classroom. Research papers in education, 21, 133-149. https://doi.org/10.1080/ 02671520600615638 . 
Ministerial Council on Education, Employment, Training and Youth Affairs. (2008). Melbourne declaration on educational goals for young Australians. Retrieved November 21, 2017 from http:// www.curriculum.edu.au/verve/_resources/National_Declaration_on_the_Educational_Goals_for_ Young_Australians.pdf.

Mockler, N., \& Groundwater-Smith, S. (2014). Methods for engaging student voice. In N. Mockler \& S. Groundwater-Smith (Eds.), Engaging with student voice in research, education and community: Beyond legitimation and guardianship (pp. 109-125). New York: Springer. https://doi.org/10.1007/ 978-3-319-01985-7.

Murillo, F. J., \& Hidalgo, N. (2017). Students' conceptions about a fair assessment of their learning. Studies in Educational Evaluation, 53, 10-16. https://doi.org/10.1016/j.stueduc.2017.01.001.

New Zealand Ministry of Education. (2017). Assessment guidance: What options are available to teachers and kaiako now that the National Standards and Ngā Whanaketanga Rumaki Māori have been removed?. Resource document. Retrieved 15 December, 2017 from http://assessment.tki.org. nz/Assessment-guidance.

Page, P. (2017). The surveillance of teachers and the simulation of teaching. Journal of Education Policy, 32, 1-13. https://doi.org/10.1080/02680939.2016.1209566.

Panadero, E. Andrade, H. Brookhart, S. (2018). Fusing self-regulated learning and formative assessment: a roadmap of where we are, how we got here, and where we are going. The Australian Educational Researcher, 45, 1-19. https://doi.org/10.1007/s13384-018-0258-y.

Peterson, E. R., \& Irving, S. E. (2008). Secondary school students' conceptions of assessment and feedback. Learning and Instruction, 18, 238-250. https://doi.org/10.1016/j.learninstruc.2007.05. 001 .

Priestley, M., Biesta, G., \& Robinson, S. (2015). Teacher agency: An ecological approach. Londo: Bloomsbury.

Rodgers, C. (2018). Descriptive feedback: Student voice in K-5 classrooms. The Australian Educational Researcher, 45, 1-16. https://doi.org/10.1007/s13384-018-0263-1.

Sadler, D. R. (1989). Formative assessment and the design of instructional systems. Instructional Science, 18, 119-144. https://doi.org/10.1007/BF00117714.

Smith, K., Gamlem, S., Sandal, A., \& Engelsen, K. (2016). Educating for the future: A conceptual framework of responsive pedagogy. Cogent Education, 3, 1-12. https://doi.org/10.1080/2331186X. 2016.1227021.

Tunstall, P., \& Gipps, C. (1996). "How does your teacher help you to make your work better?" Children's understanding of formative assessment. The Curriculum Journal, 22, 185-203. https:// doi.org/10.1080/0141192960220402.

Van der Kleij, F. M., Adie, L. E., \& Cumming, J. J. (2017). Using video technology to enable student voice in assessment feedback. British Journal of Educational Technology, 48, 1092-1105. https:// doi.org/10.1111/bjet.12536.

Willis, J. (2011). Affiliation, autonomy and assessment for learning. Assessment in Education: Principles, Policy \& Practice, 18, 399-415. https://doi.org/10.1080/0969594X.2011.604305.

Dr Lenore Ellen Adie is a Senior Research Fellow with the Assessment, Evaluation and Student Learning Research concentration in the Learning Sciences Institute Australia (LSIA), Australian Catholic University (ACU). Her research focuses on assessment and moderation processes as these contribute to supporting teachers' pedagogical practices and student learning. She has a further interest in the enactment of assessment policy and the validity of assessment processes. Sociocultural theories of learning are used in her work to interpret this dynamic context. Lenore has worked as a primary school teacher and in administration positions in state and private schools within Queensland, Australia.

Dr Jill Willis is an assessment researcher and senior lecturer in the Faculty of Education at Queensland University of Technology. She is committed to supporting teachers and school systems promote student agency and equity through their everyday assessment practices. She researches how self-assessment feedback loops inform personal and system change and how teachers adapt to assessment change. https:// eprints.qut.edu.au/view/person/Willis,_Jill.html. 
Dr Fabienne Michelle Van der Kleij is a Research Fellow in the Assessment, Evaluation and Student Learning Research Program of the LSIA at ACU. Her research covers various topics in the area of formative assessment and teacher-student student feedback interactions. Recent and ongoing research has focused on, for example, teacher and student perceptions of classroom feedback, formative assessment for diverse students, assessment for learning in classroom practice, and curriculum in the Australian context. 